\title{
Confronting the social mandate for nursing scholarship - One school of nursing's journey.
}

Susan M. Duncan

Thompson Rivers University, susanmduncan@uvic.ca

Star Mahara

Thompson Rivers University, mahara@tru.ca

Victoria Holmes

Thompson Rivers University, vholmes@tru.ca

Follow this and additional works at: https://qane-afi.casn.ca/journal

Part of the Nursing Commons

\section{Recommended Citation}

Duncan, Susan M.; Mahara, Star; and Holmes, Victoria (2014) "Confronting the social mandate for nursing scholarship - One school of nursing's journey." Quality Advancement in Nursing Education - Avancées en formation infirmière: Vol. 1: Iss. 1, Article 2.

DOI: https://doi.org/10.17483/2368-6669.1018

This Article is brought to you for free and open access by Quality Advancement in Nursing Education - Avancées en formation infirmière. It has been accepted for inclusion in Quality Advancement in Nursing Education - Avancées en formation infirmière by an authorized editor of Quality Advancement in Nursing Education - Avancées en formation infirmière. 


\section{Confronting the social mandate for nursing scholarship - One school of nursing's journey.}

\section{Cover Page Footnote}

The authors acknowledge their colleagues in the School of Nursing and the Collaborative Nursing Program of British Columbia for their commitment to advancing rigorous and relevant nursing scholarship. They acknowledge Dr. Florianne Fehr for her contribution to an earlier CASN conference presentation on nursing scholarship development. 
Schools of nursing are challenged to fulfill mandates of preparing a sustainable nursing human resource for the $21^{\text {st }}$ century and advancing the discipline and professional practice of nursing (Canadian Association of Schools of Nursing [CASN] and Canadian Nurses Association [CNA], 2014; National Institute of Nursing Research [NINR], 2011; World Health Organization [WHO], 2011). Nursing faculties around the globe are challenged to fulfill these mandates in the midst of ideological, fiscal, and human resource challenges (CASN, 2010; Emerson \& Records, 2005; Institute of Medicine, 2010; National Expert Commission (NEC), 2012; Scott et al., 2014; Thompson \& Darbyshire, 2013; Tourangeau et al., 2014). In Canada, where only $30 \%$ of nursing faculty in Canadian schools of nursing are employed in permanent positions and of those, $38 \%$ are over the age of 50 years (CNA \& CASN, 2013), the situation is further complicated by the global economic downturn. There are not only fewer qualified nursing faculty to hire, but also fewer resources to pay them in health and education sectors including the professoriate (American Association of Colleges of Nursing, 2012; Duncan et al., 2011; Wray, 2013; Yucha et al., 2014). At the same time, there are widespread calls to transform nursing education, to enhance its relevance to societal health and pay strategic attention to faculty renewal (Frenk et al., 2010; NEC; United Kingdom Department of Health, 2014; WHO; International Centre for Human Resources for Nursing, 2010). Thus, the challenge in nursing education is to ensure the most judicious use of resources including qualified faculty, time, practice education opportunities, and funding to support quality education, research, and scholarship.

In this paper, we draw on our experience at Thompson Rivers University in Kamloops, Canada where the nursing faculty has grappled with its identity during institutional transitions from community college to university-college to teaching centered university. We reflect here on the tension that exists in fulfilling our mandates of educating nursing students, contributing to the advancement of nursing education, and producing scholarship of value and relevance to the discipline. Our reflection over a span of 40 years in the life of a post-secondary institution Involves a process of conceptualizing and building capacity for scholarship within the academic setting. We offer critical reflections on implications for the development of a relevant culture of scholarship across a shifting nursing educational landscape, for promotion and tenure processes, for national accreditation of schools of nursing, and for strategically engaging in nursing research. We address the questions: For what purpose do nursing faculty engage in scholarship in diverse institutions including colleges, university colleges, and teaching centered universities? And, what does it take to develop and sustain nursing scholarship in different post-secondary institutions, not all of which are research-intensive, nor universities, and where the primary mandate is education? In addition, we offer insights that will resonate with other nurse academics facing similar institutional transitions while also building capacity for an inclusive, rigorous, and purposeful culture of scholarship. To frame the discussion of our experience of developing capacity for scholarship, we highlight literature pertaining to the development of nursing scholarship. We describe capacity building that includes faculty history, conceptualization of scholarship, infrastructure development, promotion and tenure processes, and leadership as most relevant to our development as scholars.

\section{Background}

Although nursing's research origins are traced to Florence Nightingale's epidemiological investigations in the Crimea, it is generally acknowledged that the capacity and momentum for 
nursing research is only decades old and that the need for nursing knowledge development and dissemination remains urgent. The development of the discipline of nursing is a global challenge amidst reduced funding levels for research and the increased demands on nursing faculty (Edwards \& MacDonald, 2009; Segrott et al., 2006; Thompson et al., 2010). At the same time, there is momentum and capacity in nursing research that over the past four decades continues to flourish and make a difference to population health. Capacity building for nursing scholarship, including research, is a complex process situated within the wider context of education and research policies and agendas.

The public policy context of Canadian post-secondary education is mirrored in other countries, where there is fierce competition for resources to support education, research, and innovation. In Canada, there has been a blurring of previously distinct institutional mandates of community colleges and universities (Fisher et al., 2009). Whereas colleges have previously held the mandates to offer vocational, non-degree programs in human services and trades and technology, some are now able to grant undergraduate degrees and other institutions such as our own have transitioned into special purpose universities with mandates to continue to grant certificates and diplomas as well as degrees. At the same time, governments have increased expectations that the research enterprise will fuel economic development and there is increased competition for increasingly limited resources (Metcalfe \& Fenwick, 2009; Teelken, 2012).

These developments have influenced the nursing academy in several ways. First, there is increased competition for scarce research funds from the national funding agencies resulting in most funding allocated to a few research-intensive universities. Second, there are more postsecondary institutions, including some community colleges, offering degrees in nursing which in turn raises the critical question of the form that scholarship should take in these institutions. Third, it is anticipated that the nursing shortage will be most acute in the academic sector and the problem therefore is one of how scarce human resources should be directed - for the development of the profession and the discipline (CASN, 2010; Cleary et al., 2009; Nursing Education Council of British Columbia, 2011).

With growing awareness of the current situation, nursing scholars are debating the purpose and form of nursing scholarship in the $21^{\text {st }}$ century from a variety of perspectives (Estabrooks et al., 2008; Hurley \& Taylor, 2011; Riley et al., 2002; Rolfe, 2012; Thompson \& Watson, 2013; Thoun, 2009). These debates are focused on the often competing demands for resources vested in nursing research and for the development of knowledge to advance the discipline and the practice of nursing on the one hand and to support faculty to teach nursing students on the other. This is not a new tension for nurses and nursing, rather it is one that has existed for the past century as academic nursing has evolved (Paul \& Ross-Kerr, 2011). Early in its development, Canadian Association of University Schools of Nursing (CAUSN, later CASN) identified collaboration among university schools of nursing in programs of nursing research as a strategy for building capacity (Kirkwood \& Bouchard, 1992).

While scholars cite the need for rigorous large-scale implementation studies to develop knowledge for nursing practice, there is also a renewed focus on nursing education research, and for knowledge translation in local settings. These priorities demand the attention of the nursing professoriate in collaboration with the communities they serve. As nursing education continues 
to evolve within diverse institutions that include colleges, university colleges, and universities, it is timely to consider the capacity and possibilities for addressing these priorities within these different contexts.

Capacity building for scholarship in nursing has been a focus of nursing literature in recent years, including issues pertaining to the preparation of nurses for academic roles (Arieli et al., 2009; Benner et al., 2010; Feldman \& Accord, 2002; CASN \& CNA; 2014). Institutional influences, such as leadership and infrastructure, are vital to the development of a culture of scholarship. This includes decisions about inclusivity (all faculty responsible and engaged in scholarship) and exclusivity (targeted development of a few scholars within the faculty) (Green et al., 2007). Tensions between the mandates of teaching and research and the meaning of a broad and inclusive view of scholarship in nursing, and related disciplines with practice and teaching accountabilities, must be fully explored and debated (Hofmeyer et al., 2007; Morahan \& Fleetwood, 2008; Simpson et al., 2007; Swartz, 2014). Further, defining and valuing the scholarship of teaching and practice will remain central to the development of the discipline, and therefore, it is critical that these are explicitly defined in promotion, tenure and accreditation processes (Acorn \& Osborne, 2013; Allen \& Field, 2005; Swartz).

In Canada, CASN sets national accreditation standards for schools of nursing, including those pertaining to scholarship. The CASN (2013) definition of scholarship is based on Boyer's (1990) conceptualization, with the requirement that each nursing program offering baccalaureate degrees demonstrate all forms, including discovery, teaching, integration, and application (Acorn \& Osborne). This requirement may represent a barrier for programs situated in less researchintensive universities where limited resources make it difficult to support the discovery of new knowledge through rigorous programs of research. To address the challenge of addressing all forms of scholarship, CASN is hosting symposia and workshops aimed at examining issues and challenges in the context of research and education policy. It is expected that the product of these meetings and discussions will be instructive to future directions in accreditation policy and for setting strategic priorities for nursing scholarship, including funded programs of research.

\section{Developing a Culture of Scholarship}

We turn now to our experience of developing a culture of scholarship within our School of Nursing (SON) as it transitioned from a community college to a university. We recognize how history is itself a key contextual influence on faculty culture and foundations of scholarship. In 1973, as the SON evolved from a hospital diploma program to become a two year college program, faculty emerged as a collective of teachers and practitioners in a community college where the teaching of students was clearly focused on preparing them for practice in a hospital setting. In 1989, the government of the day launched a wide scale initiative to increase access to university programs including nursing. Visionary nursing education leaders had already begun planning a collaborative nursing program that would increase access to baccalaureate programs and as such were prepared to respond with the development of the Collaborative Nursing Program of British Columbia (CNP) (Hills et al., 1994).

Collaboration in nursing education was initiated to meet the province's 2002 goal of the

baccalaureate degree as the essential educational requirement for entry into registered nurse 
practice. At its height, the CNP involved 11 partners including one university, four university colleges, and six community colleges (Zawaduk et al., 2014). The CNP governance model was founded on principles of collaboration and sharing of resources among all partners. The 11 program nursing education leaders participated as members of a steering committee with equal decision making power. All partner institutions contributed resources to hiring a program coordinator to lead curriculum, evaluation, and scholarship advancements within the collaboration. Faculty expertise and mentoring in teaching and learning innovations, scholarship, and research programs were shared in the interests of achieving the common goals of the degree requirement, program approvals, and the gold star of CASN accreditation which was achieved in 2000 and continues among current partners today.

As one of the original partners, our SON worked to conceptualize the curriculum and proceeded with the first offering of the generic baccalaureate program in 1992 (Baines, 1992; Simpson \& Abbott, 2010). In the spirit of the curriculum revolution (Bevis \& Watson, 1989; Diekelmann, 1988), the inception of this program engaged faculty in rigorous critique of existing nursing education curricula, creative development, collaboration, evaluation, and dissemination - in other words, faculty were active in the scholarship of teaching. To complement the existing cadre of college faculty, the university administration, including the director of the SON, worked to recruit faculty from a university culture to facilitate the transition to offering baccalaureate level education and developing scholarship. These individuals brought an important perspective to the SON and to influential decision-making groups, such as the institutional scholarly activity, research ethics, and academic designation committees.

In the transition from Cariboo College to University College of the Cariboo (UCC), our institution developed policy to accommodate our new mandate for research and scholarship. As one of the early programs offering degrees and developing scholarship capacity, the SON was active in campus-wide committees, contributing to the institution-wide dialogue on the nature of scholarship. By the time the institution had transitioned from a college to a university college and granted its first nursing degrees in 1996, a minority of faculty members had identified programs of scholarship within what were called "scholarly activity positions". These faculty members had teaching workload adjustments and they were evaluated according to the academic responsibilities of teaching, scholarship, and service. Although this designation of scholarly activity positions was helpful in promoting the scholarship capacity of the faculty, by modifying faculty teaching responsibilities to allow time and focus for scholarly work, it also created a feeling of inequity in that some faculty were privileged to engage in scholarship, while others were not. This tension sparked campus debates on the primary mandates of the institution (Baldwin et al., 2010).

In April of 2004; the Government of British Columbia proclaimed that UCC would become Thompson Rivers University (TRU), Canada's newest university, with the purposes of offering baccalaureate and master's degree programs, providing postsecondary training and adult basic education, and undertaking related research and scholarship activities (Thompson Rivers University Act, 2005). Leading up to the announcement and during a critical period of development, the SON and other programs transitioning to undergraduate degree programs were mentored by faculties situated in established universities in the province. These periods of 
mentorship contributed significantly to capacity development and acculturation in university values.

Since 2004, operating within full university status, there have been renewed opportunities for all faculty members to define programs of scholarship, including the scholarship of teaching, within a new - and for some, foreign - institutional context. The SON has played, and continues to play, a significant role in influencing the conceptualization of scholarship within the university as a whole. While working to define scholarship within the discipline and for professional practice, faculty members participated as chairs and members of university-wide committees to define ethical protocols for research, promotion, and tenure criteria, and to facilitate recognition and valuing of a broad expression of scholarship across the institution.

Reflecting on these institutional transitions, we recognize how history legitimates diverse expressions of scholarship that are relevant in the local context of institution, community, and the practice setting. For instance, faculty scholarship portfolios continue to reflect the early engagement and valuing of the scholarship of teaching and practice. Our collective experience of capacity building is one of conceptualizing scholarship as an inclusive and rigorous form of expression that extends to institutional and faculty mentoring and the development of infrastructure including promotion and tenure processes.

\section{Conceptualizing Scholarship}

As described, our journey to define scholarship began through our work in developing a BSN curriculum and our membership in the CNP. We participated in focused faculty development around philosophical and theoretical foundations of teaching, learning, and nursing practice. This development was intensified by our first cycle of review for accreditation with Canadian Association of University Schools of Nursing (CAUSN) in Fall 2000. We developed, modified, and extended our view through many discussions, sessions, and workshops where our faculty members explored, articulated, critiqued, and refined a conception of what scholarship entails and what it means to be a nursing scholar. Faculty members examined the work of Boyer and Glassick et al. (1997). As partners in the CNP, we also participated in faculty development initiatives, workshops, and study sessions as we sought to develop an integrated view of Boyer's four dimensions that could meet the needs of scholarship in a practice profession (Storch \& Gamroth, 2002; Zawaduk et al., 2014).

Early on, the SON contributed to the CASN definition of scholarship as one of our nursing faculty members worked on the 2004 CASN (formerly CAUSN) Task Force on Definition of Scholarship Position Statement. Both the CNP and CASN definitions evolved as an inclusive view of scholarship that provided a lens for faculty developing their teaching and nursing practice as scholarship, and for valuing a more inclusive range of expression that is central to their day to day responsibilities. To develop rigorous expressions of scholarship, the CNP Scholarship Committee worked with and adapted Glassick et al.'s criteria to describe six standards to extend scholarly work in areas where faculty were already engaged (Mahara, 2003). 
1. Scholarly activity is thoughtful. There is a clear telling of what the scholarly activity will involve/involved.

2. There is evidence of adequate preparation and inquiry into what is known. Scholarly activity follows well-defined and appropriate procedure consistent with the form of knowledge and the worldview within which the scholarship is framed.

3. Scholarly activity needs to be situated within a culture/environment that embraces and supports scholarly work and negotiates for sufficient time and resource allotments for scholarly endeavors.

4. Scholarly work is communicated to others through a variety of processes that involve peer review, public sharing, and a wider critique of the work.

5. Scholarly effort leads to a significant contribution, new understanding and knowing, new knowledge, and/or a transformation of self and others.

6. The scholar is engaged in reflective and reflexive practices.

\section{Building Infrastructure}

Developing capacity for scholarship is dependent on infrastructure - within the faculty, within the institution, and externally with other institutions and the community. In the early phase of becoming a university college, faculty worked to develop an academic designations process. Faculty members could then be identified within professorial ranks, as opposed to the generic college designation of instructor, and processes were in place to ensure rigour in the assignment of designations based on scholarly achievements, teaching expertise, and service. Nursing faculty also contributed to the establishment of the first office of research in the university as key to advocating for resources and policies in support of a broad conceptualization of scholarship, including research and external grants applications. As an early initiative, nursing faculty provided leadership for a university based committee to secure an institutional development grant for emerging universities from the Canadian Institutes of Health Research, and a nursing faculty member served as the first university delegate to this national health funding organization.

A SON scholarship committee was established in 2000 with the mandate to facilitate the ongoing presence and valuing of a broad conceptualization of scholarship in nursing, and to develop capacity among faculty and students. The committee played an essential role in positioning the SON for a national accreditation review. As one of the first scholarship committees established, its terms of reference served as a model for other schools of nursing within the collaboration. The committee ensured that scholarship was a standing agenda item for the nursing faculty council and it sponsored a newsletter citing faculty scholarly accomplishments, as well as wide ranging opportunities and possible networks.

Deep exploration of the meaning of scholarship was facilitated through questions; for instance, how does the scholarship of teaching and service differ from the traditional view of scholarship, teaching, and service, as unique and separate aspects of our academic roles? Through such questions, faculty joined the larger academic discourse occurring worldwide, particularly concerning the relationships between teaching excellence, scholarly teaching, and the scholarship 
of teaching (Allen \& Field; Kreber, 2002; Spath, 2007). At the same time, we recognized that our challenges and capacities as a SON within a new and evolving university were different than those of more established institutions. Facilitation of scholarly initiatives based on faculty interests and roles was a key function of the committee, operationalized through a series of teatime seminars focusing on the development of "half-baked ideas", grants and teams around scholarly endeavors, and opportunities for faculty to prepare and practice presentations for academic conferences. It is important to realize how the priorities of the faculty as a whole emerged as opportunities for individuals to be meaningfully involved in programs of scholarship. A key strategy was to encourage faculty to align their programs of scholarship with their teaching and practice roles and substantive areas of knowledge and expertise. Faculty also participated in strategic planning for the SON and the university, promoting the value of engaging the broader community in scholarship that matters and makes a difference in the local context.

Undergraduate student opportunities to engage with scholarship and research is the hallmark of university education for nursing, and national research funding bodies look to undergraduate institutions and programs to inspire the next generation of scholars and researchers (Sevean et al., 2005). Engaging undergraduate students in scholarship took the form of offering undergraduate research stipends and awards for nursing students to work with faculty on scholarly endeavours, including integrated literature reviews, community based symposia and focus groups, data analysis workshops, and presentations of scholarly work at conferences. Faculty participation in graduate nursing education was possible when we partnered with another university in offering their Master of Science in Nursing program on site with opportunities for faculty to teach graduate courses, and participate on student major paper and theses committees. This partnership also facilitated access to graduate education in nursing for nurses in the community, and the development of a cadre of future faculty members with preparation in the discipline of nursing.

\section{Academic Leadership}

Leadership is a key element of capacity for inspiring a culture of scholarship wherein a faculty is encouraged to develop a collective identity as scholars. Nursing faculty who had prior experience with research and inquiry took a lead role in inspiring a vision and encouraging faculty to become aware of their potential for scholarship. It was essential for the dean and chair of the program to signal the importance of scholarship by encouraging the establishment of a scholarship committee and setting the standard of faculty with advanced degrees in the discipline of nursing.

Collaboration among the nursing programs and the mentorship of the university partner was significant to the development of a culture of scholarship in all phases of our institutional and faculty development. The academic leaders of the nursing programs held the vision of an inclusive culture of scholarship with a conviction of what could be accomplished when the unique strengths of different institutions were recognized and valued. The CNP set the direction for the development of scholarship, which was taken up by the deans and directors in various ways (Storch \& Gamroth). Academic leaders in our SON believed it important to publicly acclaim the values of rigorous scholarship, including research, and its contribution to the 
university and the community as a whole. For example, the faculty was successful in nominating and awarding an Honorary Doctor of Laws to a leading Canadian nurse researcher. Her visit to accept her honorary degree included a seminar with faculty, students, and community practitioners on developing programs of research, conversations about capacity building for research in the university, and a visionary convocation address to students and the community, therefore signaling the vital contribution of nursing research within the university and the community at large.

From the outset, faculty within the institution held the vision of a comprehensive definition and approach to scholarship, one that honours the interests, talents and achievements of a diverse faculty in various phases of development. While the diversity inherent in the array of faculty members from different institutional cultures, hired over different phases of the institution, fuels creativity; it can also result in unchecked competition among individuals, as opposed to a collegial community of scholars. This challenge has required academic leaders to pay careful attention to valuing different contributions to teaching and learning and how they can be developed as scholarship of value to the discipline, and to how they are represented in promotion and tenure criteria.

\section{Promotion and Tenure Processes}

Within the current university mandate, SON promotion and tenure processes have evolved as a function of a new governance model including a senate. Processes to grant promotion and tenure were initiated in 2009, and the institution is currently living the challenge of sustaining the values of collegiality that existed within the community college years, and honouring diverse expressions of scholarship and scholarly teaching as a legitimate means of academic accountability and progression (Baldwin et al.). The university has developed collective agreement provisions for faculty promotion and tenure based on two distinct but equivalent streams for the expression of scholarship and faculty progression, known as bi-partite and tripartite roles, with faculty accountabilities for teaching and service in the former and teaching, service, and research in the latter.

The CASN (2004) position statement on scholarship influenced the work of the SON to develop promotion and tenure criteria (TRU SON, 2008). The first group of nursing faculty has moved through the promotion and tenure process and we have subsequently gained further insight into the values and rewards inherent in our evolving expression of scholarship. For instance, we see the importance of further developing criteria recognizing the scholarship of professional practice (Fiandt et al., 2004; Swartz; Thoun), particularly for faculty who are engaged in advanced nursing practice and practice education (Honig et al., 2013). Further, tri-partite faculty members will be evaluated on their ability to disseminate scholarship through refereed publications and successful acquisition of funding, as well as less traditional modes, including practice innovations, policy analyses and advocacy, and dissemination via alternate media; including Blog posts and other contemporary forms of knowledge translation. We have achieved a standard of rigorous adjudication of faculty progression as two faculty members have achieved the rank of Associate Professor in the tri-partite stream, and eight have achieved the rank of Senior Lecturer. It will continue to be important to monitor the fit between criteria for promotion and the valuing 
of activities central to the mission and sustainability of nursing education, and the discipline, while maintaining the high standards expected of academic programs and scholarship.

A significant challenge is building a culture of peer critique within a faculty where this had not previously existed. Our experience of developing criteria and modelling review processes is essential to developing rigorous programs of scholarship. In early phases however, critique must be framed in ways that contribute to faculty development in instructive and supportive venues. Debates over what constitutes promotion and tenure criteria and processes are underpinned by faculty values, leading to questions about how the various forms of scholarship should be rewarded. An essential outcome of these deliberations is the commitment to a culture of constructive criticism and credible scholarship. This is a maturation process that takes time, support, and modelling within the university and within the discipline.

\section{Exemplars and Influence}

Areas of focus and exemplars of scholarship that have emerged over the past two decades within the SON are outlined in the following Table. Faculty recognized and documented areas of focus and influence in preparation for program reviews, CASN accreditation reviews, and in the preparation of individual faculty portfolios for promotion and tenure applications. These evaluation processes have provided the structure and the opportunity to visualize areas of strength and to ensure the presence and valuing of a diverse expression of scholarship.

Today, we recognize exemplars of our collective scholarship and their defining characteristics as relating to all forms of the CASN (2013) typology. For example, the area of focus related to nursing education includes the scholarship of teaching and learning and research into teaching and learning practices, which leads to the discovery of knowledge related to curriculum. While the typology is important to describing the breadth of scholarship, we also recognize the importance of recognizing patterns in substantive areas. At this point in our development, we recognize exemplars of our collective scholarship and defining characteristics as relevant to the local context and nursing education, developed from collaborative engagement of practice and community partners, focused on health equity and vulnerable populations in the local context, and expressed through both traditional and less traditional modes of dissemination and influence. Further, there has been attention to mentoring junior faculty as an expression of the scholarship of teaching, and facilitating undergraduate students' participation in the research and scholarly dissemination processes. Over time, our scholarship has evolved to be more fully supported with external funding and to involve partnerships with other disciplines within the university and across the collaborative partnership (Cash \& Tate, 2012). 
Table 1 - Scholarship Areas of Focus, Exemplars, and Influence: 2000 - Present

\begin{tabular}{|c|c|c|c|}
\hline Area of Focus & Exemplars & Influence & $\begin{array}{l}\text { Boyer/CASN } \\
\text { Scholarship Typology }\end{array}$ \\
\hline $\begin{array}{l}\text { Nursing Education } \\
\text { Scholarship }\end{array}$ & $\begin{array}{l}\text { - Participatory and action-based research on practice education } \\
\text { innovation, partnerships, and preceptor development/supports } \\
\text { - Rural and remote health nursing and international practica } \\
\text { development and research } \\
\text { - Pedagogical innovations in specific areas: death and dying; critical } \\
\text { thinking; health promotion } \\
\text { - Critical-interpretive research and theory development on clinical } \\
\text { evaluation } \\
\text { - Historical inquiry into evolution of nursing education } \\
\text { - Local and regional grants to support initiatives } \\
\text { Development and implementation of preceptor and faculty } \\
\text { mentoring }\end{array}$ & $\begin{array}{l}\text { - } \quad \text { Participation on national task forces to influence policy guidelines } \\
\text { pertaining to clinical education in community health nursing } \\
\text { - } \quad \text { Presentations to decision-makers in health organizations } \\
\text { - } \quad \text { Local, national, and international conference presentations } \\
\text { chablications in peer reviewed venues, including nursing textbook } \\
\text { chapters } \\
\text { Book on the history of the school adds to the body of knowledge on } \\
\text { nursing education in Canada } \\
\text { - } \quad \text { Inorkshop development based on best practices } \\
\text { Innotive strategy implementation }\end{array}$ & $\begin{array}{l}\text { Integration } \\
\text { Discovery } \\
\text { Teaching-Learning }\end{array}$ \\
\hline $\begin{array}{l}\text { Population and } \\
\text { Community Health }\end{array}$ & 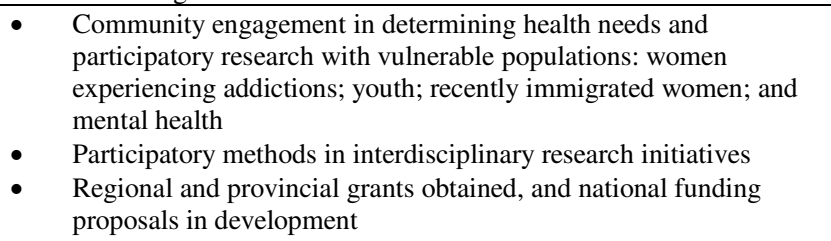 & 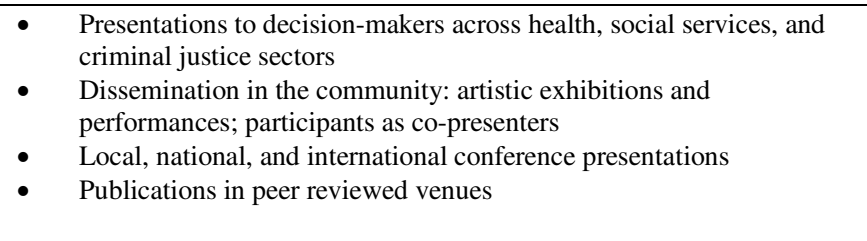 & $\begin{array}{l}\text { Application } \\
\text { Discovery } \\
\text { Teaching-Learning }\end{array}$ \\
\hline $\begin{array}{l}\text { Aboriginal Peoples' } \\
\text { Health }\end{array}$ & $\begin{array}{l}\text { - Use of decolonizing methods to engage Aboriginal communities in } \\
\text { local issues: culturally safe dementia care } \\
\text { - Community engagement to develop culturally safe nursing } \\
\text { education including strategies for the recruitment and retention of } \\
\text { students in health career programs } \\
\text { - Developing practice placements in Aboriginal health nursing } \\
\text { - Student engagement in developing knowledge for culturally safe } \\
\text { education and practice }\end{array}$ & $\begin{array}{l}\text { - } \quad \text { Community based meetings and symposia } \\
\text { - } \quad \text { Presentations to decision-makers in health organizations and } \\
\text { - } \quad \text { Povernments } \\
\text { framework and guidelines pertaining to Aboriginal peoples' health } \\
\text { - } \quad \text { Creation of policy briefs and web-based dissemination } \\
\text { - } \quad \text { Publications in peer reviewed venues } \\
\text { - Publications in non-refereed venues: Aboriginal magazines and } \\
\quad \text { community newspapers }\end{array}$ & $\begin{array}{l}\text { Discovery } \\
\text { Teaching-Learning }\end{array}$ \\
\hline $\begin{array}{l}\text { Nursing Profession and } \\
\text { Health Policy }\end{array}$ & $\begin{array}{l}\text { - Use of policy analysis methods of inquiry to develop knowledge in } \\
\text { critical areas facing the development of the nursing profession and } \\
\text { nursing organizations, professional regulation and education in the } \\
\text { context of significant transitions } \\
\text { - Historical inquiry into community health nursing } \\
\text { Health policy analysis and international comparison with local / } \\
\text { regional dissemination to health boards }\end{array}$ & $\begin{array}{ll}\text { - } & \text { Participation on national boards of directors and other leadership } \\
\text { - } & \text { Preses to inform scholarship and dissemination } \\
\text { - } & \text { Publication of policy briefs and analyses for web-based dissemination } \\
\text { - } & \text { Local, national, and international conference presentations } \\
\text { - } & \text { Publications in peer reviewed publications } \\
\text { - } & \text { Publications in non-refereed venues including Blogposts }\end{array}$ & $\begin{array}{l}\text { Application } \\
\text { Integration } \\
\text { Teaching-Learning }\end{array}$ \\
\hline
\end{tabular}




\section{Ponderings}

Reflecting on our current situation and future opportunities, we recognize the impact of a late career demographic profile of current tenured faculty on the faculty life cycle; one that urgently requires new strategies for sustaining and extending our scholarship and research. Senior faculty members, who have had the experience of developing scholarship during the formative stages of the SON, are now in the retirement phase of their careers. This brings the promise of faculty renewal as new members are beginning their academic careers, contributing a vision for curriculum and scholarship that must be nurtured through mentorship in teaching, and in developing programs of scholarship. At the same time, this new cadre of faculty is also beginning doctoral or post-doctoral programs. This renewal of a faculty requires strategic investment and judicious attention to human resource issues, not only within one SON, but across the nursing education sector as a whole. Key to the sustainability of nursing programs and to the development of the discipline of nursing will be the opportunity for faculty to access high quality doctoral programs, the majority of which must be within the discipline, with the opportunity of mentorship for faculty roles and scholarship. Based on our experience, we affirm the synergy of collaborations among faculties from diverse institutions in sustaining the essential contributions of nursing education, scholarship, and research, while responding to the unique demographic and fiscal challenges of our time.

\section{Conclusion}

We return to our question of the purpose of nursing scholarship across diverse academic environments that may or may not be situated in a university. Our reflection on the collective experience of capacity building for scholarship within the CNP and the SON leads us to conclude that nursing faculty in universities such as ours have capacity to contribute valued expertise and resources to academic partnerships, and to developing the knowledge required to advance the profession and the discipline. Essential to the $21^{\text {st }}$ century research enterprise are partnerships that expand access to populations and communities (MacDonald et al., 2013), new roles for researchers and scholars in practice (Swartz), and emerging research priorities in nursing education (National League for Nursing, 2012). We have described our experience of how our SON and the institution, through its various stages of development, was steeped in local context and capable of forming synergistic partnerships with established universities, through which contributions were maximized through faculty, student, and community engagement in scholarship. This form of dynamic collaboration has been described as the vision for health professional education and/that is rooted in academic systems involving practice, education, and research on a global scale.

In this era of diminishing resources to support nursing scholarship, faculties of nursing must think creatively and strategically about the synergistic contributions of scholars from different academic contexts. Reflecting on our experience of developing nursing scholarship over the past twenty-five years, we see that expressions of scholarship are diverse, the essence of which are examined and contested for their relevance and contribution in professional, institutional, disciplinary, and societal contexts (Allen \& Field; Hurley \& Taylor). That said, our experience tells us that although the development of high quality and socially relevant scholarship is possible within diverse institutional contexts, it must be strategically supported and envisioned in 
its formative stages (Cash \& Tate, 2012). This collective capacity can be actualized when nurses can draw on the significant experience and lessons learned from the collaborative nursing programs that have existed to advance nursing education in Canada (Molzahn \& Purkis, 2004). It is therefore timely that nursing education partners enter a new phase focused on nursing scholarship and contributing to sustainable faculty resources, nursing education excellence, and a national nursing research agenda where nursing has already made significant gains and must continue its momentum (Stewart et al., 2013). This will require the astute leadership of nursing education programs, educational institutions, and national and provincial nursing associations in partnership with governments and funding agencies.

Drawing on our experience of capacity building for nursing scholarship, we conclude that scholarship, as a way of being, cannot be disassociated from the academic enterprise of teaching and learning. Recognizing the intense challenges of faculty and fiscal resources, and shifting priorities and societal needs for nursing, means that scholarship cannot simply be an add-on to faculty roles; it must take the form of a meaningful integration of practice, education, and scholarship (Bartels, 2007; Hofmeyer et al.; Swartz; Thompson et al.). Indeed, this will require the collective capacity and partnerships of nursing education programs and leaders, across the diversity of post-secondary settings, to meet the health needs of a global society dependent on a strong and sustainable nursing education sector. To this end we take inspiration from the title of Kirkwood and Bouchard's historical monograph of the history of CAUSN: "Take counsel with one another". 


\section{References}

Acorn, S., \& Osborne, M. (2013). Scholarship in nursing: Current view. Nursing Leadership, 26(1), 24-29. doi:10.12927/cjnl.2013.23277

Allen, M.N., \& Field, P. (2005). Scholarly teaching and the scholarship of teaching. Noting the difference. International Journal of Nursing Education Scholarship, 2(1), Article 12.

American Association of Colleges of Nursing. (2012). Nursing faculty shortage fact sheet. Washington, DC: Author. Retrieved from

http://www.aacn.nche.edu/mediarelations/fact-sheets/nursing-faculty-shortage

Arieli, D., Friedman, V.J., \& Hirschfeld, M.J. (2009). The establishment of an academic nursing faculty: Action research in Israel. International Nursing Review, 56, 299-305.

doi: 10.1111/j.1466-7657.2009.00709.x

Baines, C. (1992). College-university collaboration. Canadian Nurse, 88(6), 17-19.

Baldwin, L.K., Brewer, S.E., Heaslip, P., Hunt, G.A., Jones, J.A., MacLennan, D., \& Templeman, E. (2010). Finding balance: Research and teaching at a new university. Transformative Dialogues, 4(1), 1-11.

Bartels, J.E. (2007). Preparing nursing faculty for baccalaureate level and graduate-level nursing programs: Role preparation for the academy. Journal of Nursing Education, 46, 154-158.

Benner, P., Sutphen, M., Leonard, V., \& Day, L. (2010). Educating nurses: A call for radical transformation. San Francisco, CA: Jossey-Bass.

Bevis, E.O., \& Watson, J. (1989). Toward a caring curriculum: A new pedagogy for nursing. New York, NY: NLN Press.

Boyer, E.L. (1990). Scholarship reconsidered: Priorities of the professoriate. Princeton, N.J.: Carnegie Foundation.

Canadian Association of Schools of Nursing. (2010). The case for healthier Canadians: Nursing workforce education for the $21^{\text {st }}$ century. Ottawa, Canada: CASN.

Canadian Association of Schools of Nursing. (2013). CASN position statement on scholarship in nursing. Ottawa, Canada: CASN.

Canadian Nurses Association \& Canadian Association of Schools of Nursing. (November 2013). Registered Nurse Education in Canada Statistics, 2011-2012. Ottawa, Canada: CNA.

Canadian Association of Schools of Nursing \& Canadian Nurses Association. (2014). National nursing education summary report. Ottawa, Canada: Authors.

Cash, P.A., \& Tate, B. (2012). Fostering scholarship capacity: The experience of nurse educators. The Canadian Journal for the Scholarship of Teaching and Learning, 3(1), Article 7. doi: http://dx.doi.org/10.5206/cjsotl-rcacea.2012.1.7

Cleary, B.L., McBride, A.B., McClure, M.L. \& Reinhard, S.C. (2009). Expanding the capacity of nursing education. Health Affairs, 28, 634-45. 
Diekelmann, N. (1988). Curriculum revolution: A theoretical and philosophical mandate for change. In National Leagues for Nursing (NLN) (Ed.), Curriculum revolution: Mandate for Change (pp. 137-157). New York, NY: NLN Press.

Duncan, S.M., Thorne, S., Van Neste-Kenny, J., \& Tate, B. (2011). Policy analysis and advocacy in nursing education: The Nursing Education Council of British Columbia framework. Nurse Education Today, 32, 432-437.

Edwards, N., \& MacDonald, J. (2009). Building nurses' capacity in community health services research. Journal of Nursing Education Scholarship, 6(1), Article 25.

Emerson, R.J., \& Records, K. (2005). Nursing: Profession in peril. Journal of Professional Nursing, 21, 9-15.

Estabrooks, C.A., Norton, P., Birdsell, J.M., Newton, M.S., Adewale, A.J., \& Thornley, R. (2008). Knowledge translation and research careers: Mode 1 and Mode 2 activity among health researchers. Research Policy, 37, 1066-1078. doi: 10.1016/j.respol.2008.04.06

Feldman, H.R., \& Accord, L. (2002). Strategies for building faculty research programs in institutions that are not research intensive. Journal of Professional Nursing, 18, 140-146.

Fiandt, K., Barr, K., Hille, G., Pelish, P., Pozehl, B., Hulme, P., ... Burge, S. (2004). Identifying clinical scholarship guidelines for faculty practice. Journal of Professional Nursing, 20, 147-155.

Fisher, D., Rubenson, K., Jones, G., \& Shanahan, T. (2009). The political economy of postsecondary education: A comparison of British Columbia, Ontario and Quebec. Higher Education, 57, 549-566. Retrieved from

http://www.springerlink.com/content/yl13353171435v32/

Frenk, J., Chen, L., Bhutta, Z.A., Cohen, J., Crisp, N., Evans, T., Zurayk, H. (2010). Health professionals for a new century: transforming education to strengthen health systems in an interdependent world. The Lancet, 376, 1923-1958. doi: 10.1016/S0140-6736(10)61854-5

Glassick, C., Huber, M., \& Maeroff, G. (1997). Scholarship assessed: Evaluation of the professoriate. San Francisco: Jossey-Boss.

Green, B., Segrott, J., Priest, H., Rout, A., McIvor, M., Douglas, J., ... Rushton, C. (2007). Research capacity for everyone? A case study of two academic nursing schools' capacity building strategies. Journal of Research in Nursing, 12, 247-265. doi:10:1177/1744987107078405

Hills, M.D., Lindsey, A.E., Chisamore, M., Bassett-Smith, J., Abbott, K., \& Fournier-Chalmers, J. (1994). University-college collaboration: Rethinking curriculum development in nursing education. Journal of Nursing Education, 33, 220-225.

Hofmeyer, A., Newton, M., \& Scott, C. (2007). Valuing the scholarship of integration and the scholarship of application in the academy for health sciences scholars: Recommended methods. Health Research Policy and Systems, 5(5), 1-8. doi: 10.1186/1478-4505-5-5

Honig, J., Smolowitz, J., \& Larson, E. (2013). Building framework for nursing scholarship: Guidelines for appointment and promotion. Journal of Professional Nursing, 29, 359-369. 
Hurley, J., \& Taylor, J. (2011). Nurse teaching and research: Symbiotic partners or estranged relatives. Nurse Education Today, 31, 113-114. doi: 10.1016/j.nedt.2010.07.005

Institute of Medicine. (2010). A summary of the February 2010 forum on the future of nursing: Education. Washington, DC: The National Academies Press.

International Centre for Human Resources for Nursing. (2010). The nursing community, macroeconomic and public finance policies: Towards a better understanding. Geneva: International Council of Nurses and the World Health Organization.

Kirkwood, R., \& Bouchard, J. (1992). "Take counsel with one another” A beginning history of the Canadian Association of University Schools of Nursing 1042-1992. Ottawa, Canada: CAUSN.

Kreber, C. (2002). Teaching excellence, teaching expertise, and the scholarship of teaching. Innovative Higher Education, 27, 5-23.

MacDonald, S.E., Newburn-Cook, C.V., Allen, M., \& Reutter, L. (2013). Embracing the population health framework in nursing research. Nursing Inquiry, 20(1), 30-41. doi: 10.1111/nin.12017

Mahara, M. S. (2003). Spotlight on scholarship within the Collaborative Nursing Program in BC: A summary of our work. CASN NewsUpdate (June/July), 2-6.

Metcalfe, A.S., \& Fenwick, T. (2009). Knowledge for whose society? Knowledge production, higher education and federal policy in Canada. Higher Education, 57, 209-225. doi: 10.1007/s10734-008-9142-4

Molzahn, A.E., \& Purkis, M.E. (2004). Collaborative nursing education programs: Challenges and issues. Canadian Journal of Nursing Leadership, 17(4), 41-53.

Morahan, P., \& Fleetwood. J. (2008). The double helix of activity and scholarship: Building a medical education career with limited resources. Medical Education, 42, 34-44.

National Expert Commission. (2012). A nursing call to action: The health of our nation, the future of our health system. Ottawa, Canada: Canadian Nurses Association.

National Institute of Nursing Research. (October 2011). Bringing science to life: NINR Strategic Plan. (NIH Publication \#11-7783 Maryland). Retrieved from www.ninr.nih/gov/site

National League for Nursing. (2012). NLN Research priorities in nursing education (20122015). Retrieved from http://www.nln.org/researchgrants/research priorities.pdf

Nursing Education Council of British Columbia. (2011). A policy framework for nursing education in British Columbia. Vancouver, Canada: NECBC.

Paul, P., \& Ross-Kerr, J.C. (2011). The origins and development of nursing education in Canada. In J.C. Ross-Kerr \& M.J. Wood (Eds.), Canadian nursing issues and perspectives (pp. 327-358). Toronto, Canada: Elsevier.

Riley, J.M., Beal, J., Levi, P., \& McCausland, M.P. (2002). Revisioning nursing scholarship. Journal of Nursing Scholarship, $4^{\text {th }}$ Quarter, 383-389.

Rolfe, G. (2012). Cardinal John Henry Newman and 'the ideal state and purpose of a university': Nurse education, research and practice development for the twenty-first century. Nursing Inquiry, 19, 98-106. doi:10.1111/j.1440-1800.2011.00548x 
Scott, P.A., Matthews, A., \& Kirwan, M. (2014). What is nursing in the $21^{\text {st }}$ century and what does the $21^{\text {st }}$ century health system require of nursing? Nursing Philosophy, 15, 23-24.

Segrott, J., McIvor, M., \& Green, B. (2006). Challenges and strategies in developing nursing research capacity: A review of the literature. International Journal of Nursing Studies 43, 637-651.

Sevean, P.A., Poole, K., \& Strickland, D.S. (2005). Actualizing scholarship in senior baccalaureate nursing students. Journal of Nursing Education, 44, 473-476.

Simpson, S., \& Abbott, K. (2010). Traditions and transitions: History of the nursing programs at Thompson Rivers University, 1973-2003. Gatineau, Canada: Gauvin Press.

Simpson, D., Fincher, R.M., Hafler, J.P., Irby, D.M., Richards, B.F., Rosenfeld, G.C., \& Viggiano, T.R. (2007). Advancing educators and education by defining the components and evidence associated with educational scholarship. Medical Education, 41, 1002-1009. doi:10.1111/j.1365-2923.2007.02844.x

Spath, M.L. (2007). A need for clarity: Scholarship, scholarly teaching and the scholarship of teaching and learning. Nursing Education Perspectives, 28(5), 235-236.

Stewart, M., Kushner, Kaysi E., Gray, J. \& Hart, D.A. (2013). Promoting gender equity through health research: Impacts and insights from a Canadian initiative. Global Health Promotion, 20(1), 25-38. doi: 10.1177/1757975913476903

Storch, J., \& Gamroth, L. (2002). Scholarship revisited: A collaborative nursing education program's journey. Journal of Nursing Education, 41, 524-530.

Swartz, M.K. (2014). Critical theory as a framework for academic nursing practice. Journal of Nursing Education, 53, 271-276.

Teelken, C. (2012). Compliance or pragmatism: How do academics deal with managerialism in higher education? A comparative study in three countries. Studies in Higher Education, 37, 271-290. doi: 10.1080/03075079.2010.511171

Thompson, C.J., Galbraith, M.E. \& Pedro, L.W. (2010). Building collaborative scholarship in an academic nursing community. International Journal of Nursing Education Scholarship, 7(1), Article 37. doi: 10.2202/1548-923X.1922

Thompson, D.R., \& Darbyshire, P. (2013). Is academic nursing being sabotaged by its own killer elite? Journal of Advanced Nursing 69, 1-3.

Thompson, D.R., \& Watson, R. (2013). Professing nursing or not: What's in a title? Nurse Education Today, 33, 765. http://dx.doi.org/10/1016/jedt.2013.04.018

Thompson Rivers University Act, [SBC 2005] Chapter 17. Victoria, BC: Queens's Printer.

Thompson Rivers University School of Nursing. (2008). School of Nursing Promotion and Tenure Criteria. Kamloops, Canada: Author. Retrieved from https://www.tru.ca/_shared/assets/school_of_nursing_standards15113.pdf

Thoun, D. S. (2009). Toward an appreciation of nursing scholarship: Recognizing our traditions, contributions and presence. Journal of Nursing Education, 48, 552-556. doi: 10.3928/01484834-20090716-01 
Tourangeau, A., Saari, M., Patterson, E., Ferron, E.M., Thomson, H., Widger, K., \& MacMillan, K. (2014). Work, work environments and other factors influencing nurse faculty intention to remain employed: A cross-sectional study. Nurse Education Today, 34, 940-947. http://dx.doi.org/10.1016/jnedt.2013.10.010

United Kingdom Department of Health. (2014). Delivering high quality, effective, compassionate care: Developing the right people with the right skills and the right values. A mandate from the Government to Health Education England: April 2014 to March 2015. (May 2014). Leeds: UK Government. Retrieved from www.gov.uk/dh

World Health Organization. (2011). Transformative scale up of health professional education. An effort to increase the numbers of health professionals and to strengthen their impact on population health. (WHO/HHS.HRH/HEP2011.01). Geneva: Author. Retrieved from www.who.int/hrh

Wray, J. (2013). The impact of the financial crisis on nurses and nursing. Journal of Advanced Nursing, 69, 497-499.

Yucha, C., Smyer, T., \& Strono-Perry, S. (2014). Sustaining nursing programs in the face of budget cuts and faculty shortages. Journal of Professional Nursing, 30, 5-9. doi:10.1016/j.profnurs.2013.07.002

Zawaduk, C., Duncan, S., Mahara, M.S., Tate, B., Callaghan, D., McCullough, D., ... Van Neste-Kenny, J. (2014). Mission possible: Twenty-five years of university and college collaboration in baccalaureate nursing education. Journal of Nursing Education, 53, 580588. doi: 10.3928/01484834-20140922-048 